\title{
Bur open Spatial analysis of health effects of large industrial incinerators in England, 1998-2008: a study using matched case-control areas
}

\author{
Nicola F Reeve, ${ }^{1}$ Thomas R Fanshawe, ${ }^{1}$ Thomas J Keegan, ${ }^{1}$ Alex G Stewart, ${ }^{2}$ \\ Peter J Diggle ${ }^{1}$
}

To cite: Reeve NF, Fanshawe TR, Keegan TJ, et al. Spatial analysis of health effects of large industrial incinerators in England, 1998-2008: a study using matched case-control areas. BMJ Open 2013;3: e001847. doi:10.1136/ bmjopen-2012-001847

- Prepublication history and additional material for this paper are available online. To view these files please visit the journal online (http://dx.doi.org/10.1136/ bmjopen-2012-001847).

Received 26 July 2012 Revised 5 December 2012 Accepted 21 December 2012

This final article is available for use under the terms of the Creative Commons Attribution Non-Commercial 2.0 Licence; see http://bmjopen.bmj.com
${ }^{1}$ Faculty of Health and Medicine, Lancaster University, Lancaster, UK ${ }^{2}$ Centre for Public Health, Liverpool John Moores University, Liverpool, UK

Correspondence to Nicola F Reeve; n.reeve@lancaster.ac.uk

\section{ABSTRACT}

Objectives: To assess whether residential proximity to industrial incinerators in England is associated with increased risk of cancer incidence and mortality.

Design: Retrospective study using matched casecontrol areas.

Setting: Five circular regions of radius $10 \mathrm{~km}$ near industrial incinerators in England (case regions) and five matched control regions, 1998-2008.

Participants: All cases of diseases of interest within the circular areas.

\section{Primary and secondary outcome measures:}

Counts of childhood cancer incidence ( $<15$ years); childhood leukaemia incidence ( $<15$ years); leukaemia incidence; liver cancer incidence; lung cancer incidence; non-Hodgkin's lymphoma incidence; allcause mortality; infant mortality ( $<1$ year) and liver cancer mortality.

Results: The estimated relative risks for case circles versus control circles for the nine outcomes considered range from 0.94 to 1.14 , and show neither elevated risk in case circles compared to control areas nor elevated risk with proximity to incinerators within case circles.

Conclusions: This study applies statistical methods for analysing spatially referenced health outcome data in regions with a hypothesised exposure relative to matched regions with no such exposure. There is no evidence of elevated risk of cancer incidence or mortality in the vicinity of large industrial incinerators in England.

\section{INTRODUCTION}

The disposal of solid waste is an increasing problem in developed countries as space for landfill sites runs out. Incineration is an attractive solution as it reduces the weight and volume of waste, and prevents growth of pathogenic bacteria and the spread of disease vectors, while also providing an opportunity to recover thermal energy for electricity generation. ${ }^{12}$

\section{ARTICLE SUMMARY}

Article focus

- Research specific to waste incinerators has provided mixed evidence for the effects of proximity to incinerators on health.

- Older incinerators have been associated with increased incidence and mortality from selected cancers, while more recent reports show little association.

- Despite this, the effect of incinerator emissions remains a public health issue.

\section{Key messages}

- Our results show no evidence of elevated risk for individuals living in areas containing an incinerator compared to individuals living in matched areas without an incinerator.

- Moreover, within areas, there is little evidence of an increase in risk for those living in close proximity to an incinerator compared to those living further away.

Strengths and limitations of this study

- The strengths of this study include adjustment for the age/sex structure and deprivation of the underlying population at a small-area level. The design using matched areas reduces the need to adjust for circle-level risk factors for which data are unavailable.

- Limitations include the long lead times for adult cancers and use of distance rather than modelled or directly measured pollution levels as a proxy for exposure. Data are at small-area level, making adjustment for individual risk factors such as smoking status infeasible.

Incineration produces emissions of carbon dioxide $\left(\mathrm{CO}_{2}\right)$ and water $\left(\mathrm{H}_{2} \mathrm{O}\right)$. Emissions can also include acid gases (hydrogen chloride, hydrogen fluoride and sulfur dioxide), nitrogen oxides, heavy metals (cadmium, mercury, arsenic, vanadium, chromium, cobalt, copper, lead, manganese, nickel, thallium and tin), polychlorinated biphenyls 
(PCBs), polycyclic aromatic hydrocarbons (PAHs) and dioxins, although emissions of dioxins can be minimised by keeping the combustion temperature above $1100^{\circ} \mathrm{C}$. Residual ash from solids is also produced, and may contain aluminium, calcium, silicates, iron, sodium, magnesium, potassium, lead and zinc. ${ }^{1}$ The International Agency for Research in Cancer (IARC) considers some of these substances to be potentially carcinogenic to humans ${ }^{3}$; in particular, some heavy metals and PAHs are classified as either Group 1 (carcinogenic to humans) or Group 2A (probably carcinogenic to humans) with several others classified as Group 2B (possibly carcinogenic to humans). PCBs are classified as Group 2A. Exposure to these substances may occur either by air or by consumption of contaminated food. Possible effects include reproductive impairment and carcinogenesis. ${ }^{1}$

There is ongoing public concern over the extent to which emissions produced by industrial incinerators may have an adverse effect on human health. Several studies have investigated this potential risk by applying a variety of spatial statistical methods to both small area-level and individual-level data, ${ }^{4-7}$ although they have had limited ability to control for confounding factors such as deprivation and other industrial emissions.

While studies of older incinerators have found evidence of an adverse health effect, reports based on data from newer incinerators show little association. Recent reviews have noted that there is low risk of adverse health effects due to residency close to incinerators and any effects are probably not measurable. ${ }^{8}{ }^{9}$ They base this view on assessments of the effects of air pollutants on health and the fact that modern (post-European Directive 2000/76/EC) incinerators only contribute a small amount to local air pollution. ${ }^{10}$

Though there is now considerable literature investigating the possible elevation in disease risk in the vicinity of an industrial point source, work specific to incinerators has provided mixed evidence for the effects of proximity to incinerators on health. Elliott $e t a \tilde{\varphi}$ found excess cancers in people living in close proximity to municipal solid waste incinerators (observed/expected ratios for 0 $3 \mathrm{~km}$ from the incinerator ranged from 1.04 for all cancers and colorectal cancer to 1.13 for liver cancer), but suspected residual confounding. Kim et $a l^{11}$ also found adverse health effects in the vicinity of solid waste incinerators, with an attributable burden of $0.2 \%$ and $0.1 \%$ of the total burden of respiratory disease and cardiovascular disease, respectively, in Seoul in 2007. Porta et $a l^{12}$ report an increased risk in cancer of $3.5 \%$ for people living close to old incinerators but note that studies suffer from limitations due to poor exposure assessment, ecological level of analysis and lack of information on relevant confounders. Most of these, and other studies, ${ }^{13-17}$ are concerned with older incinerators, and their results may not be applicable to incinerators currently in operation and under tighter regulatory control.

Other studies found no evidence of association of health risks with incinerators: Gouveia and Ruscitto ${ }^{2}$ investigated various cancers in Brazil; Vilavert et $a l^{18}$ monitored the concentrations of polychlorinated dibenzo- $p$-dioxins and dibenzofurans in a region in Spain containing an incinerator; Elliott $e t a l^{19}$ studied cancer of the larynx and lung in Britain; Vinceti et $a l^{7}$ focused on congenital abnormalities in Italy. None of these studies reported an effect. In a review of studies concerned with waste management, Rushton ${ }^{20}$ states that the body of literature does not support concerns about proximity to waste disposal, since results vary for different cancer sites and many studies are unable to take into account confounding factors such as socioeconomic status.

The aim of this study was to investigate whether large-scale incinerators in England have an impact on the health of the people living close to them. Our study used a novel design in which circular case regions containing an incinerator were matched to similar control regions without an incinerator, rather than using the more common method of matching individuals. ${ }^{4} 2122$ The main objectives were (1) to investigate whether there are differences in the incidences of health outcomes between case and control circles, taking into account some possible confounding factors; (2) to investigate whether incidence within circles varies according to proximity to an incinerator and (3) to set a baseline for future work that allows for prolonged lead times in adult carcinogenesis. To undertake this, we conducted a retrospective analysis of the spatial distribution of selected adverse health outcomes in the vicinity of large-scale incinerators in England. We compared health outcome counts at a population level in case and control regions, adjusting for deprivation, age and sex, and using distance from the incinerator as a proxy measure of exposure.

\section{METHODS}

The study period was 1998-2008. We included all municipal waste incinerators in England with a capacity in excess of 150000 tonnes per annum (tpa) of waste material that were operational on or before 31 December 1998 and for at least 5 years subsequently. This time period was chosen as the EU Waste Incineration Directive ${ }^{10}$ came into force in December 2003 for new plants and for existing plants in December 2005, allowing time for retrofitting equipment to meet the directive. This identified seven incinerators, but we excluded two incinerators sited in London as they were less than $20 \mathrm{~km}$ apart, making it impossible to identify suitable matching control regions, as described below.

The unit of geography used in this study is the Lower Layer Super Output Area (LSOA) of the UK census. There are 34378 LSOAs in England and Wales, with a minimum population of 1000 and a mean population of 1500. Case circles around each incinerator were defined as the set of all LSOAs whose geometric centroid was contained within a circle of radius $10 \mathrm{~km}$ centred on the 
incinerator. Guided by previous literature, ${ }^{25}$ we chose this radius to be of sufficient size to include the area in which any health effects are likely to be observable, without being so large that effects would be masked.

Control circles were selected as follows. For each Local Authority (LA) containing an incinerator, we identified the most similar LA using criteria defined by the Office for National Statistics (ONS) and explained in detail on its website. ${ }^{23}$ This measure was created by combining census data variables representing key characteristics of the area, including: demographic structure, household composition; housing; socioeconomic character; employment; and industry sector. The centroid of each selected LA was determined using MapInfo, and a circle of radius $10 \mathrm{~km}$ centred on this point was drawn. The control circle was defined as the set of all LSOAs whose centroids fell within the selected circle, provided that no incinerator with a capacity in excess of 50000 tpa lay within it or within $10 \mathrm{~km}$ of its boundary. When this occurred, the second most similar match was used, which was necessary only for the Stoke-on-Trent/ Sunderland pairing. ${ }^{24}$ The five case circles with their matched control circles are mapped in figure 1. We determined the geometric centroid of each LSOA in each case or control region, and used this to establish the distance of each LSOA from the incinerator.

From the ONS we obtained, for each LSOA, annual counts of the following health outcomes, chosen as those most likely to have a biologically plausible association with incinerator by-products ${ }^{12}$ : childhood cancer incidence $\left(<15\right.$ years, ICD-10 codes $\left.\mathrm{C} 00-97^{25}\right)$; childhood

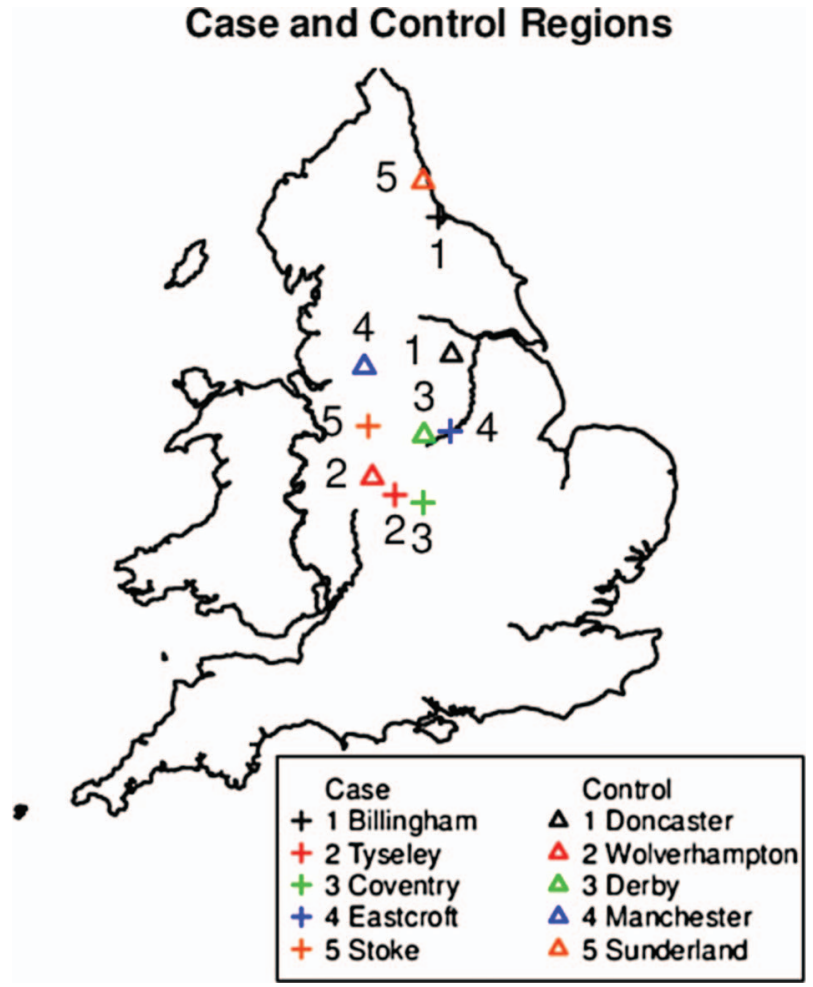

Figure 1 Locations of case and control regions. leukaemia incidence ( $<15$ years, C91-95); leukaemia incidence (C91-95); liver cancer incidence (C22); lung cancer incidence (C34); non-Hodgkin's lymphoma incidence (C82-85); all-cause mortality; infant mortality $(<1$ year) and liver cancer mortality (C22).

We also obtained LSOA-level population counts, by 5 -year age groups and sex, for $2001 .^{26}$ We used the English Indices of Deprivation $2004^{27}$ as an index of multiple deprivation (IMD); this also uses 2001 census data. The IMD is a single summary measure based on seven domains of deprivation: Income Deprivation; Employment Deprivation; Health Deprivation and Disability; Education, Skills and Training Deprivation; Barriers to Housing and Services; Crime; and Living Environment Deprivation.

\section{Models}

We calculated expected counts for each LSOA in the study and for each health outcome using indirect standardisation by applying the national age and sex-specific incidence or mortality rate to the age-sex structure of the LSOA. ${ }^{28}$ We then considered two models. Model 1 investigates the temporal trend at circle level and establishes the importance or otherwise of including the temporal effect in subsequent analysis; Model 2 uses time-aggregated data and includes a function that allows for smoothly varying risk with increasing distance from the incinerator site.

\section{Model 1: temporal analysis}

Here, we use health outcome data aggregated over all LSOAs within each circle. The expected count obtained using indirect standardisation is included in the model as an offset, $\mathrm{E}_{\mathrm{ijt}}$ for the ith pair $(\mathrm{i}=1, \ldots, 5)$ and $\mathrm{jth}$ circle $(j=1,2)$ in year $t(t=1, \ldots, 11), w_{i j}$ represents IMD, $\varepsilon_{i}$ indicates membership of pair $i$ and $v_{j}$ indicates case/control status ( 1 for case circles, 0 for control circles). The model assumes that the count, $Y_{\mathrm{ijt}}$, for the ith pair and jth circle in year $t$ is such that:

where

$$
\mathrm{Y}_{\mathrm{ijt}} \sim \operatorname{Poisson}\left(\mu_{\mathrm{ijt}}\right)
$$

$$
\mu_{\mathrm{ijt}}=\mathrm{E}_{\mathrm{ijt}} \exp \left(\alpha+\beta \mathrm{w}_{\mathrm{ij}}+\varepsilon_{\mathrm{i}}+\eta \mathrm{v}_{\mathrm{j}}+\tau \mathrm{t}\right)
$$

and where $\sim$ means 'is distributed as'.

\section{Model 2: multiplicative factor for distance}

We adapt the model used by Diggle et at to explore the possible effect of proximity to the incinerator. As population and IMD data originate from the 2001 census, we are unable to include LSOA-level offsets corresponding to individual years in this model. We therefore aggregate over time: $Y_{\mathrm{ijk}}$ denotes the total number of cases over the study period, in the ith pair, jth circle and kth LSOA, and $\mathrm{E}_{\mathrm{ijk}}$ the corresponding expected count. 
Distance to the incinerator, $\mathrm{d}_{\mathrm{ijk}}$, is included as a covariate in a continuous function $\mathrm{g}\left(\gamma, \zeta, \mathrm{d}_{\mathrm{ijk}}\right)$ with two parameters: one for the elevation in disease risk at the source $(\zeta)$ and one for the decay in risk as distance increases $(\gamma)$. The model is

$$
\mathrm{Y}_{\mathrm{ijk}} \sim \operatorname{Poisson}\left(\mu_{\mathrm{ijk}}\right)
$$

where

$$
\mu_{\mathrm{ijk}}=\mathrm{E}_{\mathrm{ijk}} \exp \left(\alpha+\beta \mathrm{w}_{\mathrm{ijk}}+\varepsilon_{\mathrm{i}}+\eta \mathrm{v}_{\mathrm{j}}\right) \mathrm{g}\left(\gamma, \zeta, \mathrm{d}_{\mathrm{ijk}}\right)
$$

and

$$
\mathrm{g}\left(\gamma, \zeta, \mathrm{d}_{\mathrm{ijk}}\right)=1+\zeta \exp \left[-\left(\mathrm{d}_{\mathrm{ijk}} / \gamma\right)^{2}\right] \mathrm{v}_{\mathrm{j}}
$$

We also fit this model with $\left(\mathrm{d}_{\mathrm{ijk}} / \gamma\right)^{2}$ replaced by $\mathrm{d}_{\mathrm{ijk}} / \gamma$ to check the effect of the functional form of distance on the results.

\section{Overdispersion}

Where overdispersion is observed (ie, variance greater than the mean), we use the method described by McCullagh and Nelder, ${ }^{29}$ which accounts for this by adjusting the model-based SEs. As this method is only valid when there is no residual spatial correlation, we apply the diagnostic test for residual spatial correlation used by Fanshawe et $a l,{ }^{30}$ comparing the sample correlation of the distances between LSOA centroids and the squared differences between their residuals to that obtained by repeated random assignment of residuals. We also carry out tests of deviance to compare different models, allowing for overdispersion. ${ }^{31}$

\section{Confidence intervals}

All CIs presented are 95\% CIs, calculated as point estimates \pm 1.96 SEs.

\section{RESULTS}

In this section, we first describe the results of an initial, exploratory analysis and then report the results of the models outlined in the Methods section.

\section{Initial analysis}

A simple illustration of the potential effect of distance from the incinerator, and of any differences between case circles, is given by the cumulative standardised mortality/incidence ratio (SMR/SIR) for each health outcome for each circle as distance from the incinerator increases. This is shown in figure 2. This figure shows substantially higher SMRs/SIRs in some circles than in others, but does not suggest a trend in relation to distance from the incinerator for most case circles for most health outcomes. SIR estimates for childhood leukaemia are subject to large sampling variability, especially at small distances, because counts are smaller than for the other outcomes.

Table 1 summarises deprivation and the age-sex structure for all case and control circles. Several variables used in the matching algorithm ${ }^{23}$ are also shown-for these variables, values are taken from the 2001 Census for either the LA in which the incinerator is located or the LA with which it is matched.

Differences in IMD percentiles between matched circles are small. Across the whole study region, the
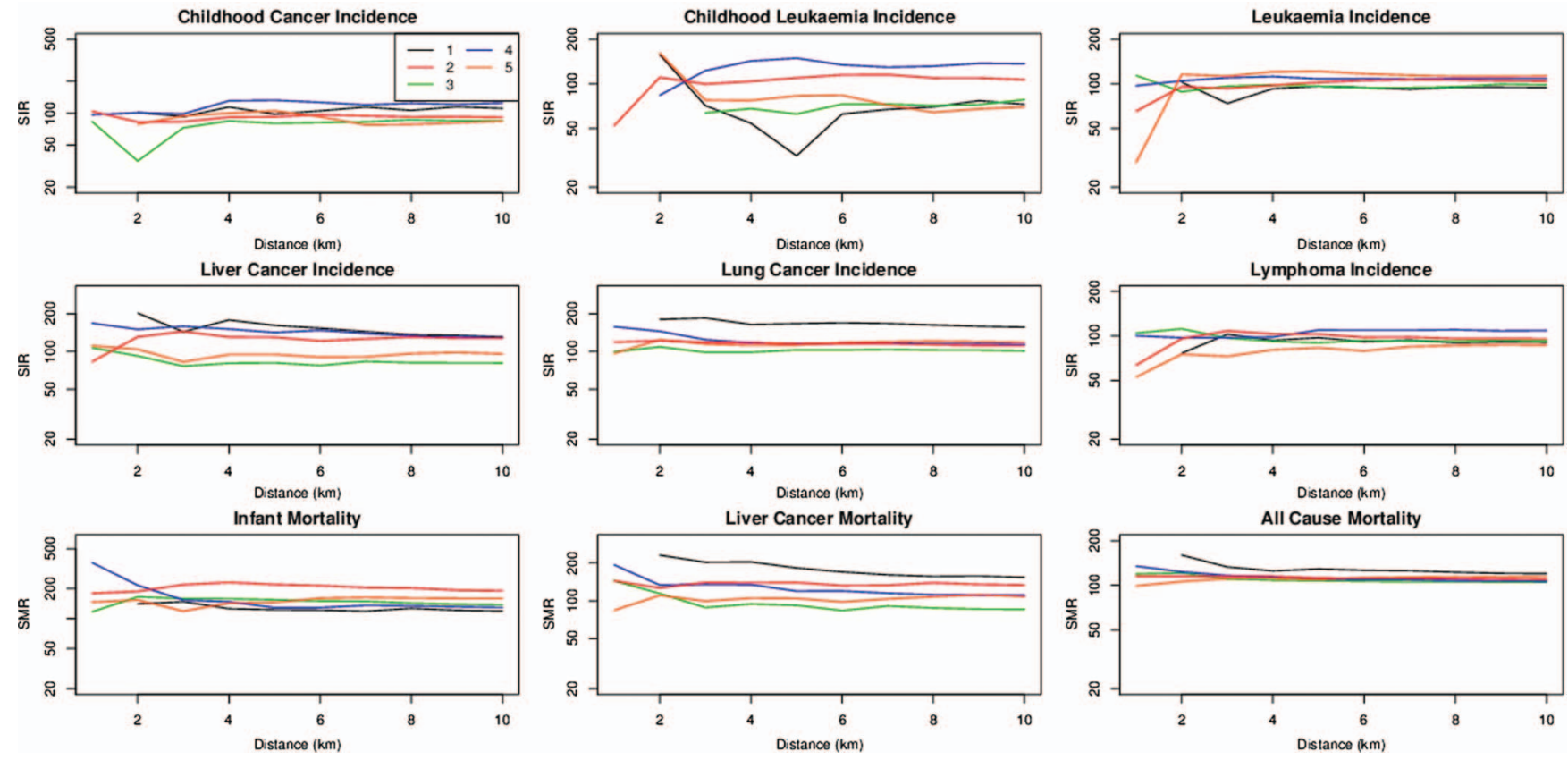

Figure 2 Estimated standardised mortality/incidence ratios (SMRs/SIRs) for each health outcome with respect to distance to the centre of the circle (case circles only). Line numbers correspond to case circles shown in figure 1. Vertical axis is plotted on logarithmic scale. 


\begin{tabular}{|c|c|c|c|c|c|c|c|c|c|c|c|c|c|}
\hline & \multicolumn{3}{|l|}{ Totals } & \multicolumn{2}{|l|}{ Pair 1} & \multicolumn{2}{|l|}{ Pair 2} & \multicolumn{2}{|l|}{ Pair 3} & \multicolumn{2}{|l|}{ Pair 4} & \multicolumn{2}{|l|}{ Pair 5} \\
\hline & $\begin{array}{l}\text { Case } \\
\text { circles }\end{array}$ & $\begin{array}{l}\text { Control } \\
\text { circles }\end{array}$ & $\begin{array}{l}\text { All } \\
\text { circles }\end{array}$ & Case & Control & Case & Control & Case & Control & Case & Control & Case & Control \\
\hline \multicolumn{14}{|l|}{ IMD (percentiles) } \\
\hline 25 th & 15.58 & 15.86 & 15.74 & 16.13 & 16.06 & 18.92 & 15.58 & 13.14 & 8.81 & 12.26 & 16.64 & 16.07 & 18.36 \\
\hline 50th & 28.79 & 29.53 & 29.24 & 33.08 & 28.34 & 35.76 & 31.18 & 21.90 & 20.33 & 23.53 & 29.98 & 26.58 & 30.94 \\
\hline 75th & 47.40 & 45.62 & 46.59 & 53.20 & 45.52 & 51.13 & 42.70 & 35.71 & 33.75 & 42.88 & 51.54 & 42.72 & 44.62 \\
\hline Male (\%) & 49.05 & 48.96 & 49.00 & 48.52 & 48.89 & 48.93 & 49.00 & 49.76 & 49.17 & 49.43 & 49.06 & 48.63 & 48.55 \\
\hline \multicolumn{14}{|l|}{ Age } \\
\hline Mean & 41.40 & 41.57 & 41.48 & 41.19 & 41.46 & 41.11 & 41.53 & 41.54 & 41.65 & 41.82 & 41.48 & 41.68 & 41.82 \\
\hline SD & 12.04 & 12.05 & 12.05 & 12.00 & 11.98 & 11.95 & 11.91 & 12.14 & 12.10 & 12.30 & 12.14 & 11.93 & 12.11 \\
\hline Population (/100 000) & 26.57 & 25.72 & 52.29 & 3.89 & 2.25 & 10.18 & 5.89 & 3.75 & 2.83 & 5.22 & 10.48 & 3.53 & 4.27 \\
\hline $\begin{array}{l}\text { Population density } \\
\text { (people per hectare) }\end{array}$ & 27.45 & 24.39 & 25.92 & 8.75 & 5.05 & 36.49 & 34.07 & 30.50 & 28.41 & 35.78 & 33.97 & 25.75 & 20.43 \\
\hline Not born in UK (\%) & 9.23 & 7.97 & 8.60 & 3.00 & 2.87 & 16.50 & 11.24 & 13.01 & 8.55 & 9.94 & 14.78 & 3.72 & 2.40 \\
\hline $\begin{array}{l}\text { Single-person } \\
\text { household (\%) }\end{array}$ & 17.84 & 16.80 & 17.32 & 14.56 & 12.69 & 18.65 & 16.20 & 16.52 & 16.48 & 23.39 & 24.41 & 16.09 & 14.23 \\
\hline HE qualifications (\%) & 15.20 & 15.31 & 15.25 & 15.17 & 11.78 & 16.62 & 13.63 & 16.73 & 17.73 & 17.62 & 21.42 & 9.87 & 11.97 \\
\hline Unemployment (\%) & 4.78 & 4.67 & 4.72 & 4.98 & 4.20 & 5.71 & 5.32 & 3.96 & 4.00 & 5.25 & 5.02 & 3.99 & 4.81 \\
\hline
\end{tabular}

mean age is 41.48 years, and $49 \%$ of all people in the study are male. There is little difference in the values of these factors averaged over all case circles, compared with all control circles. In each individual circle, the average age and the sex ratio are very similar to the overall average. Population counts between case and control circles within pairs vary, but we adjust for this using standardisation to calculate expected counts, as described in the Methods section.

The first part of table 2 shows average unstandardised yearly numbers of cases for each outcome in both case and control circles. Most outcomes have similar average counts in case and control circles; apparent exceptions are leukaemia incidence and infant mortality, which have higher average counts in case circles (329 and 260, respectively) than in control circles (289 and 202, respectively), and lung cancer incidence, which is higher in control circles (2077) than in case circles (1861). Figure 3 shows temporal trends in SMRs/SIRs. Although all-cause mortality shows a gradual decline in raw count over time, its SMR shows an increasing temporal trend in both case and control regions. Similarly, increasing temporal trends in SMR/SIR are apparent for infant mortality and lung cancer incidence. Temporal trends in case and control circles are similar for all outcomes.

\section{Model-specific analysis}

Model 1: temporal analysis

The effect of year was statistically significant, showing an increasing trend over time, for leukaemia, liver cancer and lung cancer incidence, and all-cause, infant and liver cancer mortality (table 2, last three columns). For the outcomes showing a larger temporal effect, there were only small differences in the trend for case circles compared with control circles (figure 3). In addition, the population and IMD data originated from the 2001 census, and we were therefore unable to include the correct LSOA-level offsets corresponding to individual years in this model. For these reasons, we aggregated data over time before fitting models for spatial variation within circles.

\section{Model 2: multiplicative factor for distance}

The effect of distance from an incinerator for each outcome is indicated by the parameters for the elevation in risk at the source and the decay in risk $(\zeta$ and $\gamma)$. As the estimate of disease risk at a given distance is a combination of these two parameters, it is not possible to convert the individual parameter estimates to a simple relative risk (RR). Instead, the estimates of these two parameters are shown in table 3. Parameter estimates for non-Hodgkin's lymphoma incidence and liver cancer mortality had very large SEs and so are not reported. In addition, the likelihood function for liver cancer incidence was flat and showed no appreciable improvement in fit compared to a model with the $\mathrm{g}\left(\gamma, \zeta, \mathrm{d}_{\mathrm{ijk}}\right)$ term removed, so results from the latter model are shown for this variable (table 3 ). Table 4 shows the results of analysis of deviance for model comparison. There was no difference in fit between using squared distance and distance. Although there is some improvement in fit for infant mortality and lung cancer mortality for the model that includes distance compared to the model that ignores distance, there was no evidence of increased risk close to the incinerator for these or any other outcomes, as the $\zeta$ parameter that represents this increase in risk was either negative or not significantly different from zero.

There was a statistically significant increase in risk for each unit increase in IMD of $1.7 \%$ for infant mortality, $1.5 \%$ for lung cancer incidence and less than $1 \%$ for liver cancer incidence and mortality and all-cause mortality (table 3).

The RR of living in a case circle compared with living in a control circle for leukaemia incidence was 1.137 (95\% CI 1.065 to1.213), but it was not significant for any other outcome except all cause mortality, for which the effect is in a counter-intuitive direction, with RR 0.965 (95\% CI 0.947 to 0.984 ). For leukaemia incidence, there was no evidence of a gradient in risk according to distance from the incinerator (table 3). 
Table 2 Total counts of health outcomes and relative risks (95\% Cls) from Model 1: Temporal analysis

\begin{tabular}{|c|c|c|c|c|c|c|}
\hline \multirow[t]{2}{*}{ Health outcome } & \multicolumn{3}{|c|}{ Total count } & \multirow[b]{2}{*}{ IMD $(\exp (\beta))$} & \multirow[b]{2}{*}{$\begin{array}{l}\text { Case circle versus } \\
\text { control circle }(\exp (\eta))\end{array}$} & \multirow[b]{2}{*}{ Year $(\exp (\tau))$} \\
\hline & $\begin{array}{l}\text { All } \\
\text { circles }\end{array}$ & $\begin{array}{l}\text { Case } \\
\text { circles }\end{array}$ & $\begin{array}{l}\text { Control } \\
\text { circles }\end{array}$ & & & \\
\hline $\begin{array}{l}\text { Childhood cancer } \\
\text { incidence }\end{array}$ & 135 & 70 & 65 & $0.996(0.974$ to 1.018$)$ & $1.040(0.936$ to 1.157$)$ & 0.990 (0.974 to 1.006$)$ \\
\hline $\begin{array}{l}\text { Childhood } \\
\text { leukaemia } \\
\text { incidence }\end{array}$ & 45 & 23 & 22 & 0.985 (0.949 to 1.023$)$ & $1.005(0.837$ to 1.206$)$ & $1.004(0.976$ to 1.032$)$ \\
\hline $\begin{array}{l}\text { Leukaemia } \\
\text { incidence }\end{array}$ & 618 & 329 & 289 & 0.997 (0.987 to 1.007$)$ & $1.135(1.080$ to 1.192$)$ & $1.010(1.002$ to 1.018$)$ \\
\hline $\begin{array}{l}\text { Liver cancer } \\
\text { incidence }\end{array}$ & 293 & 142 & 151 & $1.032(1.017$ to 1.048$)$ & $0.982(0.913$ to 1.056$)$ & $1.024(1.012$ to 1.035$)$ \\
\hline $\begin{array}{l}\text { Lung cancer } \\
\text { incidence }\end{array}$ & 3939 & 1861 & 2077 & $1.027(1.022$ to 1.031$)$ & $0.905(0.887$ to 0.923$)$ & $1.011(1.008$ to 1.014$)$ \\
\hline $\begin{array}{l}\text { Non-Hodgkin's } \\
\text { lymphoma } \\
\text { Incidence }\end{array}$ & 820 & 406 & 413 & $0.993(0.984$ to 1.002$)$ & $0.986(0.945$ to 1.028$)$ & 1.004 (0.997 to 1.010$)$ \\
\hline All-cause mortality & 54009 & 26750 & 27259 & $1.006(1.005$ to 1.007$)$ & $0.958(0.953$ to 0.963$)$ & 1.011 (1.010 to 1.012$)$ \\
\hline Infant mortality & 462 & 260 & 202 & $1.015(1.003$ to 1.028$)$ & $1.118(1.054$ to 1.186$)$ & 1.025 (1.016 to 1.034$)$ \\
\hline $\begin{array}{l}\text { Liver cancer } \\
\text { mortality }\end{array}$ & 256 & 129 & 127 & 1.035 (1.018 to 1.052$)$ & $1.008(0.933$ to 1.089$)$ & $1.014(1.003$ to 1.026$)$ \\
\hline
\end{tabular}

After adjusting for overdispersion, the fit was adequate. The residual spatial correlation was significant for childhood cancer and lung cancer incidence and infant mortality, with $\mathrm{p}$ values of $0.02,<0.001$ and 0.01 , respectively. For these outcomes, the correlations were all less than 0.019. As these correlations are small, we conclude that the spatial dependence is negligible, making the correction for overdispersion reliable. In
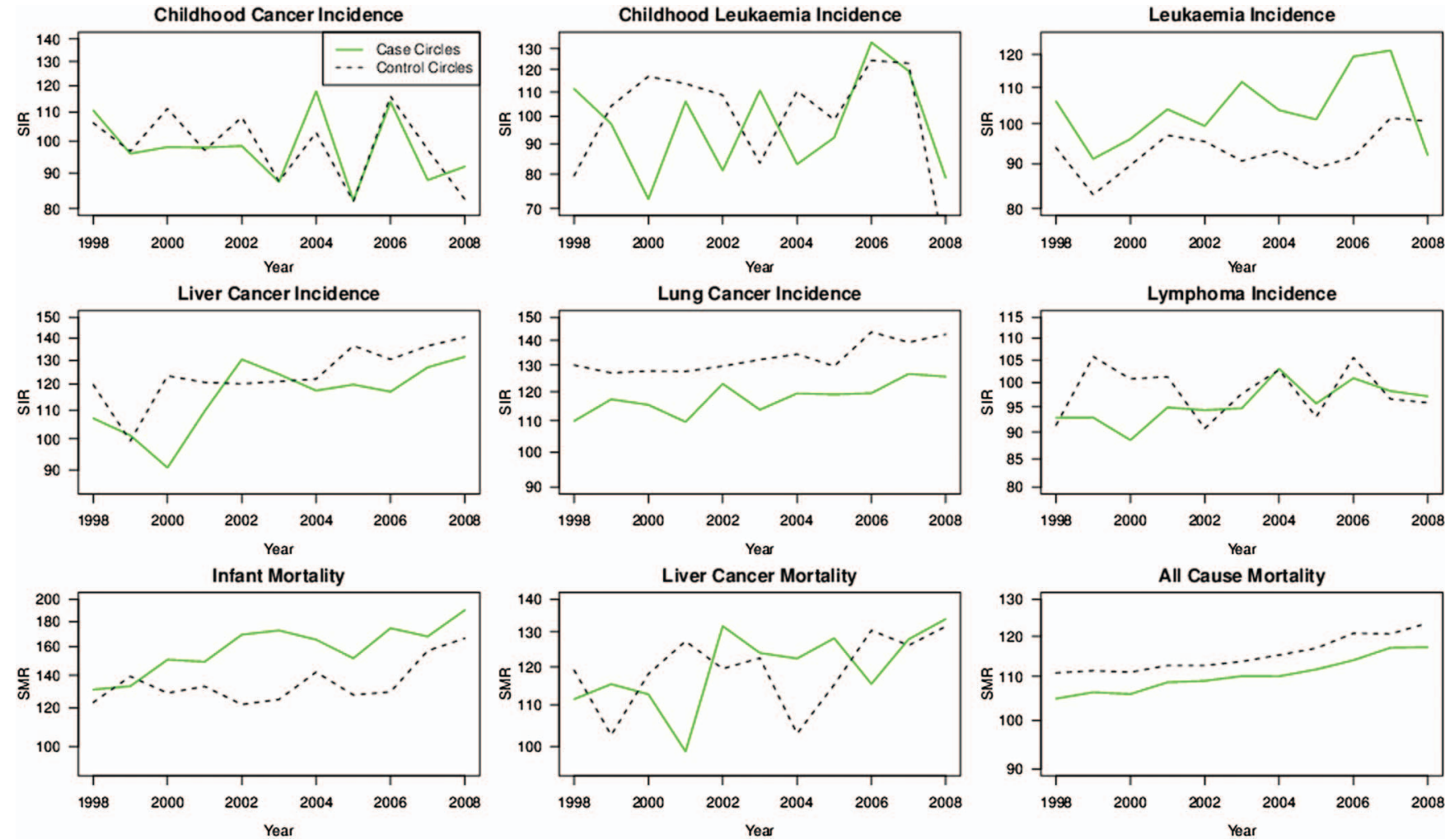

Figure 3 Estimated standardised mortality/incidence ratios (SMRs/SIRs) over time for each health outcome, averaged across case and control circles. Vertical axis is plotted on the logarithmic scale. 
Table 3 Relative risks and parameter estimates (95\% Cls) from Model 2

\begin{tabular}{|c|c|c|c|c|}
\hline Health outcome & IMD $(\exp (\beta))$ & $\begin{array}{l}\text { Case circle versus } \\
\text { control circle }(\exp (\eta))\end{array}$ & $\begin{array}{l}\text { Change in risk at } \\
\text { source }(\zeta)\end{array}$ & $\begin{array}{l}\text { Rate of decay } \\
(\mathbf{k m}(\gamma))\end{array}$ \\
\hline $\begin{array}{l}\text { Childhood } \\
\text { cancer incidence }\end{array}$ & $0.999(0.997$ to 1.002$)$ & $1.059(0.797$ to 1.407$)$ & $-0.281(-4.404$ to 3.842$)$ & 1.715 (0 to 8.151$)$ \\
\hline $\begin{array}{l}\text { Childhood } \\
\text { leukaemia } \\
\text { incidence }\end{array}$ & 0.998 (0.993 to 1.002$)$ & $1.023(0.704$ to 1.486$)$ & $-0.650(-12.320$ to 11.020$)$ & 1.148 (0 to 7.120$)$ \\
\hline $\begin{array}{l}\text { Leukaemia } \\
\text { incidence }\end{array}$ & 0.999 (0.998 to 1.000$)$ & $1.137(1.065$ to 1.213$)$ & $-0.472(-6.043$ to 5.099$)$ & 0.682 (0 to 2.891$)$ \\
\hline $\begin{array}{l}\text { Liver cancer } \\
\text { incidence }\end{array}$ & $1.009(1.007$ to 1.010$)$ & $0.984(0.914$ to 1.060$)$ & ${ }^{2}$ & - \\
\hline $\begin{array}{l}\text { Lung cancer } \\
\text { incidence }\end{array}$ & $1.015(1.014$ to 1.015$)$ & $0.936(0.874$ to 1.003$)$ & $-0.096(-0.188$ to -0.004$)$ & 3.598 (0 to 8.624$)$ \\
\hline $\begin{array}{l}\text { Non-Hodgkin's } \\
\text { lymphoma } \\
\text { incidence }\end{array}$ & 0.999 (0.998 to 1.000$)$ & $0.987(0.945$ to 1.031$)$ & - & - \\
\hline $\begin{array}{l}\text { All-cause } \\
\text { mortality }\end{array}$ & $1.008(1.008$ to 1.009$)$ & $0.965(0.947$ to 0.984$)$ & $0.187(-0.469$ to 0.843$)$ & 0.762 (0 to 1.944$)$ \\
\hline Infant mortality & 1.017 (1.015 to 1.019$)$ & $0.974(0.600$ to 1.582$)$ & $0.225(-0.529$ to 0.980$)$ & 6.454 (0 to 15.715$)$ \\
\hline $\begin{array}{l}\text { Liver cancer } \\
\text { mortality }\end{array}$ & $1.008(1.006$ to 1.010$)$ & $1.004(0.928$ to 1.086$)$ & - & - \\
\hline
\end{tabular}

addition, plots of residuals (pooled across all circles) against distance from the incinerator and against direction from incinerator did not reveal any systematic trends, suggesting that the modelling assumptions are reasonable (see online supplementary material).

\section{DISCUSSION}

We have presented the results of a study of the health effects of large industrial incinerators in England between 1998 and 2008. Across a broad range of outcomes that have been linked to pollutants released by incinerators in previous studies, our results show no elevated risk for individuals living in areas containing an incinerator compared to individuals living in matched areas without an incinerator.

In the models that constitute the main analysis, we made allowances for both the age-sex structure of the underlying population, through indirect standardisation, and the key confounder of deprivation, measured at the small-area (LSOA) level. The results of fitting a continuous risk function to reflect the patterns of risk of specific outcomes across regions containing an incinerator need to be interpreted carefully. There was an apparently increased risk of leukaemia incidence for those living in case regions, but for this outcome the distance effect was non-significant and the trend, counter-intuitively, was towards a decreased risk in the vicinity of the incinerator.

For all outcomes considered, within case circles, there is little evidence of an increase in risk for those living in proximity to an incinerator compared to those living further away. One might have anticipated a doseresponse relationship with distance from the incinerator if the incinerators were responsible for causing an elevation in disease or mortality risk. The fact that no such relationships emerged supports our general conclusions.

Others ${ }^{13-17} 3233$ have used dispersion modelling of emissions to further define exposure, particularly of dioxins, proven carcinogens. In this study, we chose to use a distance-based proxy measure of exposure because we did not have accurate retrospective data on locationspecific emissions, and there remain doubts about the accuracy of air dispersion model outputs in this setting, especially when they cannot be validated against reliable measurements from monitoring networks. ${ }^{34}$

Part of the background to this study is the continuing community concern about incinerators, a concern which does not discriminate incinerators by emissions. Although it is possible that incinerator emissions differ between sites, they are likely to be more consistent over time and space than is sometimes suggested, combustion conditions being more important than precursor waste content. This supports our decision to treat incinerators at different sites as if they are homogeneous units, although differences in emissions between sites or over time may reduce the power of our study to identify authentic health effects.

Although some of the cancers we examined may have longer lead times from exposure to clinical disease than the period covered by the study, infant mortality and some of the childhood cancers have much shorter lead times, less than the 10 years covered by the period of the present study. For the adult cancers, repeating our study at an appropriate interval, based on the same sites which are now subject to more stringent controls than before 2005, may go some way to address this issue. 


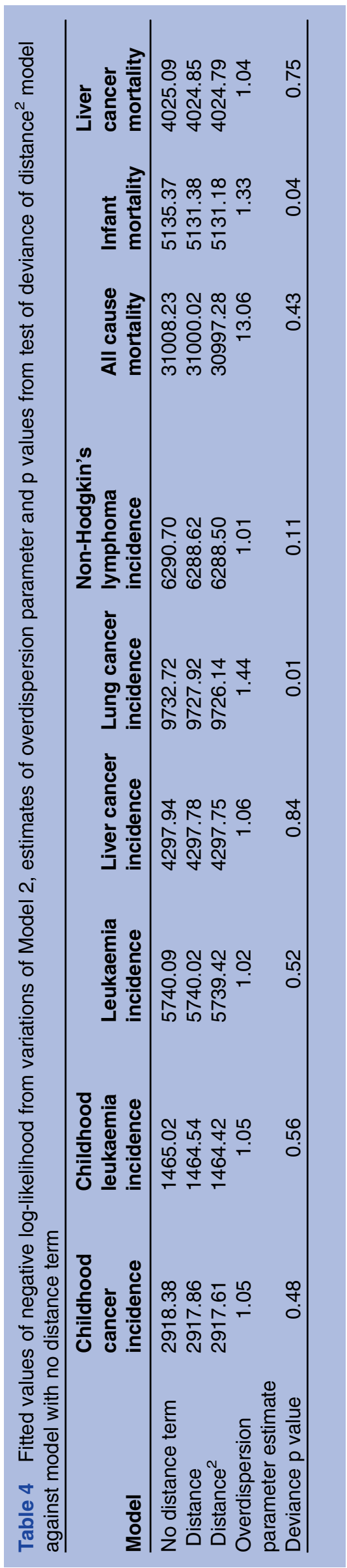

Exploratory analysis showed substantial differences in case numbers between different circles, possibly due to factors such as increased levels of deprivation. This emphasised the importance of including the pairing as a factor in the model. While no clear effect of distance from the incinerator was observed, it is possible that a distance effect was masked by other factors not taken into account in these plots, such as the deprivation of the area.

Higher counts in case circles than control circles were observed for leukaemia incidence and infant mortality (table 1). This may indicate a potential incinerator effect, but may also be at least partially explained by other factors. In particular, this initial analysis makes no adjustment for the age-sex structure of the regions or differences in deprivation level.

Several other factors relating to the design and nature of the study may explain our findings. In common with other studies in this field, ${ }^{5}$ ours may suffer from unobserved confounding factors that our analysis has been unable to address. Although the dataset, based on official data from the ONS, is as comprehensive as could be expected for a study of this type, our analysis is based on small-area-level data, and therefore we are unable to adjust for individual-level risk factors such as smoking status, diet and genetic risk factors, which are strongly associated with many of the outcomes considered. ${ }^{35-39}$

Higher levels of deprivation are strikingly linked to increased incidence in many of the disease outcomes we have considered: all-cause and infant mortality, lung cancer incidence and liver cancer incidence and mortality. The decision to employ a circle-matched design in this study, in which case and control circles were also matched on a variety of other socioeconomic factors, reduced the need to adjust for many of these factors explicitly in our analysis but does not entirely eliminate it. Also, while the IMD is a generally accepted summary measure of deprivation, it cannot fully capture aspects of deprivation that may affect the risk for specific diseases. In addition, we did not take into account other sources of local air pollution. This may be a beneficial avenue for future studies to explore.

The statistical methods used in our analysis include a continuously decaying distance function model, which provided an adequate fit and gives additional information about the likely effect of distance on disease risk. Diggle et at and Lawson ${ }^{40}$ have suggested fitting step function models, which include a plateau of constant elevated risk up to an unknown distance $\delta$, and models allowing for angular direction from a point source. When we attempted to fit these models to our data, we found that parameter estimates were unstable. Further research is needed to evaluate the practical feasibility of fitting these models to area-level data.

In summary, our findings broadly support those of previous research, ${ }^{2} 1920$ even though the residential histories of the individuals contributing to this study are unknown and many of the cancers considered have long 
lead times. It may require a carefully constructed individual-level cohort study, possibly also using validated dispersion modelling of emissions, to address these concerns definitively.

Contributors NFR carried out the data analysis and literature review and wrote the paper. TRF contributed to the data analysis, interpretation of results and writing of the paper. TJK contributed to the literature review, identification of data sources and interpretation of results. AGS contributed to the study design and identification of data sources. PJD contributed to the study design and interpretation of results. All authors approved the final manuscript.

Funding This research received no specific grant from any funding agency in the public, commercial or not-for-profit sectors.

Competing interests NFR is funded by a studentship from the Medical Research Council.

Provenance and peer review Not commissioned; externally peer reviewed.

Data sharing statement No additional data are available.

\section{REFERENCES}

1. Colls J. Air pollution. 2nd edn. London and New York: Spon Press, 2002: chapter 1.7.

2. Gouveia N, Ruscitto RP. Spatial analysis of the health risks associated with solid waste incineration: a preliminary analysis. Rev Bras Epidemiol 2010;13:3-10.

3. International Agency for Research in Cancer. IARC monographs on the evaluation of carcinogenic risks to humans: polychlorinated dibenzo-para-dioxins and polychlorinated dibenzo-furans. Lyon: IARC, 1997;69.

4. Biggeri A, Barbone F, Lagazio $C$. et al. Air pollution and lung cancer in Trieste, Italy: spatial analysis of risk as a function of distance from sources. Environ Health Perspect 1996;104:750-4.

5. Elliott $P$, Shaddick G, Kleinschmidt I,, et al. Cancer incidence near municipal solid waste incinerators in Great Britain. Br J Cancer 1996;73:702-10.

6. Diggle $\mathrm{P}$, Morris S, Elliott $\mathrm{P}$, et al. Regression modelling of disease risk in relation to point sources. J $R$ Stat Soc Ser $A$ 1997; 160:491-505

7. Vinceti M, Malagoli C, Fabbi S, et al. Risk of congenital anomalies around a municipal solid waste incinerator: a GIS-based case-control study. Int J Health Geogr 2009;8:8-17.

8. COC. Update Statement on the Review of Cancer Incidence near Municipal Solid Waste Incinerators, COC/09/S2. March 2009 http:// www.iacoc.org.uk/statements/documents/COC09S2Update statementonCancerlncidenceandMSWIsMarch09.pdf (accessed 12 Jun 2012)

9. Maynard RL, Walton H, Pollitt F, et al. The Impact on Health of Emissions to Air from Municipal Waste Incinerators. Health Protection Agency (London), RCE 13. 2010. http://www.hpa.org.uk/webc/ HPAwebFile/HPAweb_C/1266228112244 (accessed 12 Jun 2012).

10. Directive $2000 / 76 / E C$ of the European Parliament and of the Counci of 4 December 2000 on the incineration of waste. http://europa.eu/ legislation_summaries/environment/waste_management/l28072_en htm (accessed 26 Oct 2012).

11. Kim Y-M, Kim J-W, Lee H-J. Burden of disease attributable to air pollutants from municipal solid waste incinerators in Seoul, Korea: a source-specific approach for environmental burden of disease. Sci Total Environ 2011;409:2019-28.

12. Porta D, Milani S, Lazzarino Al, et al. Systematic review of epidemiological studies on health effects associated with management of solid waste. Environ Health 2009;8:60.

13. Floret $\mathrm{N}$, Viel J-F, Lucot $\mathrm{E}$, et al. Dispersion modeling as a dioxin exposure indicator in the vicinity of a municipal solid waste incinerator: a validation study. Environ Sci Technol 2006;40:2149-55.

14. Floret N, Lucot E, Badot P-M, et al. A municipal solid waste incinerator as the single dominant point source of PCDD/Fs in an area of increased non-Hodgkin's lymphoma incidence. Chemosphere 2007;68:1419-26.

15. Zambon $P$, Ricci $P$, Bovo E, et al. Sarcoma risk and dioxin emissions from incinerators and industrial plants: a population-based case-control study (Italy). Environ Health 2007;16:19.
16. Viel J-F, Clément M-C, Hägi M, et al. Dioxin emissions from a municipal solid waste incinerator and risk of invasive breast cancer: a population-based case-control study with GIS-derived exposure. Int J Health Geogr 2008;7:4.

17. Cordier S, Lehébel A, Amar E, et al. Maternal residence near municipal waste incinerators and the risk of urinary tract birth defects. Occup Environ Med 2010;67:493-9.

18. Vilavert L, Nadal M, Mari M, et al. Monitoring temporal trends in environmental levels of polychlorinated dibenzo-p-dioxins and dibenzofurans: results from a 10-year surveillance program of a hazardous waste incinerator. Arch Environ Contam Toxicol 2010;59:521-31.

19. Elliott P, Beresford J, Jolley D, et al. Cancer of the larynx and lung near incinerators of waste solvents and oils in Britain. In: Elliott $P$ Cuzick J, English D, Stern R., eds. Geographical and environmental epidemiology: methods for small-area studies. New York: Oxford University Press, Inc, 1997: 359-67.

20. Rushton L. Health hazards and waste management. Br Med Bull 2003;68:183-97.

21. Dolk H, Vrijheid $\mathrm{M}$, Armstrong $\mathrm{B}$, et al. Risk of congenital anomalies near hazardous-waste landfill sites in Europe: the EUROHAZCON study. Lancet 1998;352:423-7.

22. Diggle PJ, Morris SE, Wakefield JC. Point-source modelling using matched case-control data. Biostatistics 2000;1:89-105.

23. Office for National Statistics. Methods for national statistics 2001 area classification for local authorities. 2001. http://www.ons.gov.uk/ ons/guide-method/geography/products/area-classifications/ ns-area-classifications/index/methodology-and-variables/ local-authorities/index.html (accessed 12 Jun 2012)

24. Office for National Statistics. Methods for national statistics 2001 corresponding local authorities. $2001 \mathrm{http}: / /$ www.ons.gov.uk/ons/ guide-method/geography/products/area-classifications/ ns-area-classifications/index/corresponding-authorities/ local-authorities/index.html (accessed 8 Oct 2012).

25. World Health Organisation International Classification of Disease (ICD-10). http://www.who.int/classifications/icd/en (accessed 8 Oct 2012).

26. Office for National Statistics, 2001 Census: Standard Area Statistics (England and Wales). ESRC/JISC Census Programme, Census Dissemination Unit, Mimas (University of Manchester)

27. Office of the Deputy Prime Minister. The English Indices of Deprivation 2004 (revised). 2007. http://www.communities.gov.uk/ publications/communities/englishindices (accessed 12 Jun 2012).

28. Woodward M. Epidemiology: study design and data analysis. 2nd edn. Boca Raton: Chapman \& Hall/CRC, 2005:176-84.

29. McCullagh P, Nelder JA. Generalized linear models. 2nd edn London and New York: Chapman and Hall, 1989.

30. Fanshawe TR, Diggle PJ, Rushton S, et al. Modelling spatio-tempora variation in exposure to particulate matter: a two-stage approach. Environmetrics 2008;19:549-66.

31. Smyth GK. Generalized linear models with varying dispersion. $J R$ Stat Soc Ser B 1989;51:47-60.

32. Viel J-F. GIS and atmospheric diffusion modeling for assessment of individual exposure to dioxins emitted from a municipal solid waste incinerator. Geotechnol Environ 2011;4:443-56.

33. Ma X-J, Jiang X-G, Jin Y-Q, et al. Dispersion modeling and health risk assessment of dioxin emissions from a municipal solid waste incinerator in Hangzhou, China. J Zhejiang Univ Sci A 2012;13:69-78.

34. Gulliver J, de Hoogh K, Fecht D, et al. Comparative assessment of GIS-based methods and metrics for estimating long-term exposures to air pollution. Atmos Environ 2011;45:7072-80.

35. Bell D, Taylor J, Paulson D, et al. Genetic risk and carcinogen exposure: a common inherited defect of the carcinogen-metabolism gene glutathione S-transferase M1 (GSTM1) that increases susceptibility to bladder cancer. J Natl Cancer Inst 1993;85:1159-64

36. Goodwin J, Brodwick M. Diet, aging, and cancer. Clin Geriatr Med 1995;11:577.

37. Kleinman J, Pierre M Jr, Madans J, et al. Effects of maternal smoking on fetal and infant mortality. Am J Epidemiol 1988;127:274-82.

38. Koop C, Luoto J. The health consequences of smoking: Cancer. Overview of a report of the surgeon general Public Health Rep 1982;97:318.

39. Stellman S, Resnicow K. Tobacco smoking, cancer and social class IARC Sci Publ 1997:138:229-50.

40. Lawson $A B$. On the analysis of mortality events associated with a pre-specified fixed point. J $R$ Stat Soc Ser A 1993;156:363-77. 